\title{
Recessive dystrophic epidermolysis bullosa inversa
}

INSERM

\section{Source}

INSERM. (1999). Orphanet: an online rare disease and orphan drug data base. Recessive dystrophic epidermolysis bullosa inversa. ORPHA:79409

Recessive dystrophic epidermolysis bullosa inversa (RDEB-I) is rare subtype of dystrophic epidermolysis bullosa (DEB, see this term) characterized by blisters and erosions which are primarily confined to intertrig inous skin sites, the base of the neck, the uppermost back, and the lumbosacral area. 